\title{
A QUESTÃO DA "ALIENAÇĀO" EM KARL MAPX - O Exemplo da Obra de Arte - (sugestões para um debate)
}

\author{
ANA MARIA CHIAROTTI DE ALMEIDAa
}

\section{RESUMO}

O presente trabalho discute, a partir de alguns textos de Karl Marx, as condições de "alienação" às quais os homens es. tão submetidos na sociedade capitalista. Esta "alienação" ultrapassa as questões puramente objetivas ou ligadas ao caráter da produção material, alcançando a "interioridade" dos sujeitos e estruturando as suas subjetividades. Esse debate ao mesmo tempo em que levanta questões importantes sobre a essência da sociedade capitalista, permite a emergência de reflexões sobre a relação individuo e sociedade. Especialmente, ao enfatizar a contradição entre a natureza criadora, transformadora e ativa do homem e a forma como estas dimensões se expressam no modo de produção capitalista. Ou seja, ao estar submetido às leis da produção capitalista o ser do homem como ser livre e criador é negado. Portanto, perde a possibilidade de desenvolver as suas potencialidades e de produzir livremente e universalmente.

\section{PALAVRAS-CHAVE: Alienação; Fetichismo; Mercadoria; Objetividade; Subjetividade; Indivíduo; Sociedade}

\section{1 - APRESENTAÇÃO}

O presente ensaio ao sugerir um debate sobre a questão da "alienação" na sociedade capitalista, tenta resgatar algumas dimensões sobre a relação indivíduo e sociedade, articuladas a elementos objetivos, isto é, a partrir das condições materiais de produção, bem como indicar alguns caminhos para a discussão da alienação do homem, perceben. do que esta ultrapassa o elemento material, alcançando a própria "interioridade" dos sujeitos, fazendo parte da estruturação de suas subjetividades.

Para tanto, em um primeiro momento teceremos algumas considerações a respeito das condiç̃es de "alienação" às quais os homens estão submetidos na sociedade capitalista, com base nas discussões realizadas por Karl Marx em "O trabalho alienado", contidas na parte final dos seus Manuscritos econômico-filosóficos de 1844, em "Fetichismo da Mercadoria", na sua obra "O Capital" e em "O dinheiro como relação social", nos Grundisse (Marx, 1971, $1975,1983)$. Em um segundo momento tentaremos perceber, através de um exemplo concreto - a obra de arte - como a questão da alienação, sob as condições da produção capitalista, envolve a questão da individualidade e sua articulação com a reificação das relações sociais.

Cabe ressaltar que não é objeto do presente trabalho realizar uma discussão sobre as idéias estéticas de Karl Marx e muito menos oferecer um debate aprofundado da relação obra de arte e capitalismo.

$\mathrm{Na}$ realidade, ao utilizarmos este exemplo, procuramos, de um lado, perceber como podemos buscar em fatos do cotidiano da existência humana, subsídios para melhor compreender, numa situação histórica concreta, como se dão as relações entre indivíduo e sociedade. Por outro lado, nossa intenção é a de lançar algumas questões que poderiam servir de base à futuras reflexões e pesquisas, como por exemplo, sobre a capacidade dos sujeitos, através de suas ações, intervirem no curso da história, alterando as condições nas quais se encontram alienados, construindo, desse modo, a experiência de liberdade.

Estas questões são muito bem analisadas por Castoriadis (1986) ao considerar a relação de ineréncia existente entre o indivíduo e o social/histórico. Segundo esse autor é no terreno dessa inerência onde são possíveis a descoberta, a constituição do novo e das novas maneiras de viver. Dito de outra maneira, é o lugar da criação e da instituição de um novo modo de constituir-se e de relacionar-se com o instituído.

Apesar da argumentação do presente ensaio enfatizar a subjetividade sob a perspectiva da alienação, o leitor deve ter claro que as questões acima são plenamente pertinentes à continuidade de um debate sobre a relação indivíduo e sociedade capitalis, a fim de não incorrer no risco de uma interpretação ingênua acerca da "alienação" sob o ponto de vista do método dialético. 


\section{2 - "ALIENAÇÃO": OBJETIVIDADE E SUBJETIVI- DADE - O EXEMPLO DA "OBRA DE ARTE"}

Se estamos preocupados em realizar algumas reflexð̃es sobre a relação indivíduo e sociedade, no modo de produção capitalista, necessariamente temos que resgatar as discussões realizadas por Karl Marx, sobre um elemento básico da própria fundamentação dessa sociedade - o trabalhador livre - assalariado - que tem a sua força de trabalho transformada em mercadoria, condição essencial para existência e reprodução do capital, constituindo a base das relações de classes e da propriedade privada ao capitalismo. (Silveira $\mathrm{Fi}$. tho, 1986).

A proposta de Marx é justamente constatar esse fato histórico e, com isto, através de uma análise crítica, desvendar a essência da sociedade capitalista, buscando a sua su. peração.

Para tanto, demonstra ser fundamental procurar entender a forma de trabalho dominante nesta sociedade, resultando na alienação total do homem, que sob as leis da produção capitalista se apresenta enquanto trabalhador livre, isto é, como uma mercadoria.

Estas análises apontam que este modo de trabalho o trabalho alienado - desenvolve um processo de alienação do trabalhador em relação ao produto de seu trabalho e a própria atividade do mesmo, resultando com isto na aliena. ção da essencia do homem, na medida em que atinge o seu şer genérico, isto $e$, deformando todas as faculdades humanas, alienando-o da natureza de si mesmo.

Desta forma as dicussões de Marx sobre o trabalho alienado ultrapassam as questões puramente objetivas ligadas ao caráter da produção material, apesar de tê-las como ponto de partida, colocando-nos frente a uma dimensão que diz respeito a própria constituição do ser desse trabalhador; é o ser do homem que está em questão.

Apesar deste último aspecto merecer, ao longo deste trabalho, uma atenção especial de nossas discussões, só poderemos entende lo se nos detivermos mais demoradamente na análise sobre a alienação do trabalhador em relação ao produto de seu trabalho e à própria atividade do trabalho.

Como bem ressalta Marx "... o objetivo que o traba. tho produz, o seu produto, se the defronta como um ser alheio, com um poder independente do produtor. A realização efetiva do trabalho é a sua objetivação. No estado econômico-político esta realização efetiva do trabalho aparece como desefetivação do trabalhador, a objetivação como perda e servidão do objeto, a apropriação como alienação, como exteriorizaçăo". (Marx, 1983)

Uma vez submetido à leis da produção capitalista, o trabalhador deve produzir mercadorias em larga escala para permitir uma grande acumulação de capital, que é, por sua vez, empregada na produção de mais mercadorias.

Neste processo, o trabalhador, além de vender sua força de trabalho ao Capitalista, através de um contrato salarial, permite que o capital tenha o poder de dispor dos produtos de seu trabalho. Com isto, se estabelece uma não identificação do trabalhador com o objeto de seu trabaIho, significando uma perda da possibilidade de apropriação do resultado de sua atividade - a relação é de estra120 nhamento - o que resulta em.uma autorização do objeto em relação ao sujeito, isto é, o objeto se afirma com um poder independente ao próprio sujeito que o produziu.

Sobre esîe fato histórico de o trabalhador se relacio. nar com o produto de seu trabalho enquanto objeto aheio. Marx esclarece que "... quanto mais o trabalhador se gasta trabalhando, tão mais poderoso se toma o mundo objetivo alheio que ele cria frente a si, tão mais pobre se torna ele mesmo, o seu mundo interior, tanto menos coisas the pertencem como suas próprias". (Marx, 1983)

$\mathrm{Na}$ essência desta discussão está contida a própria questão da relação Homem a Natureza. A Natureza, ao se constituir no material sobre o qual o trabalho se realiza e produz, oferece tanto os meios de subsisténcia do trabaIhador quanto os meios de vida do trabatho. Porerrt, nas condiçôes de produçáo capitalista, o objeto a atividade do rrabalho nâo pertencem ao sujeiro: aste é condicionado por aspectos exteriores. A Naturaza tom um significado de soisa, através da autonomizaça do objeto e, enquanto sujeitos físicos, dependemos dela.

"... o trabalhador se torna portanto um servo do seu

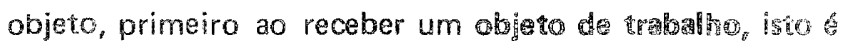

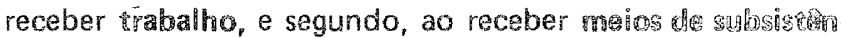
cia. Portanto, para que possa existir primeiro como êaba.

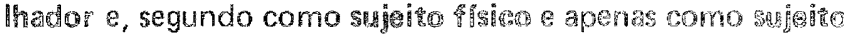
Pisiga ele é trabahador". (Marx, 1983)

Esta relaço se apresenta para o rabahador enquanto

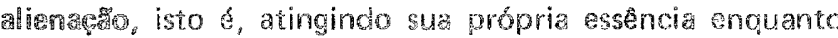
sujeito, na medida em que \& sua vida, posta no objeto, näo the pertence mais, the exterior. Portom, este relaça de alienação só pode se concretizar através do processo de pro. dução. Portanto, é dentro da própria atividade produtiva que podemos perceber a efetivação desta exterioridade, pois é no ato da produçå que o trabalhador se aliena de si pró prio.

"O trabalhador alienado do seu produto está, ao mesmo tempo, alienado de si mesmo. Seu próprio trabaho não é mais seu, e o fato de que se torne propriedade de outro anuncia uma expropriaçăo que atinge a essencia mesma do homem" (Marcurse, 1978)

Isto significa que a atividade do rabalho, longe de atender as necessidades físicas a mentais do trabalhador, de ser um meio de auto-realizaçễo de desenvolvimento de suas potencialidades, nega a sua própria existência humana, transformando-o em mercadoria, deformando todas as suas faculdades humanas.

O trabalho não se constitui um meio de satisfação de uma necessidade, mas uma forma para a saxisfaça de neces. sidades exteriores ao individuo.

Neste sentido Marx afirma que "O trabalho exterior, o trabatho no qual o homem se exterioriza, \& um trabaho de auto-sacrifício, de mortificação. Finalmente, a exterioridade do trabalho aparece, para o trabalhador, no fato de que o trabalho não é seu próprio, mas sim de outro, que não the pertence, que nele ele não pertence a si mesmo, mas a um outro (...) é a perda de si mesmo". (Marx, 1983)

Deste modo podemos afirmar que o trabalhador, ao manter uma relação de alienaç̃o frente ao produto de seu trabalho e à própria atividade do trabalho, está alienado 
também da Natureza e de si mesmo, atingindo a sua essên. cia; arrancando-the a sua vida genérica, the tira o seu corpo inorgânico - a Natureza. O que significa o homem estar alienado do homem e a desumanização completa do trabaIhador.

Esta dimensão da alienação - do ser genérico - possibilita-nos perceber que é o ser do homem que se coloca como questão, ultrapassando o plano material, alcançando a própria subjetividade do homem trabalhador.

Portanto, o que está em foco não é estritamente a alienação material, mas a alienação da subjetividade do sujeito.

Se o ser do homem só se define enquanto homem trabalhador, a sua realização como ser genérico depende de suas relações com a Natureza, considerando-a extensão de seu próprio e, consequentemente; as relações de classes, tornam-se naturalizadas, isto é, são relações apreendidas e experienciadas como naturais, perdendo sua historicidade.

Karl Marx em Grundrisse (Marx, 1971), no item "O dinheiro como relação social", ressalta essa dependéncia do indivíduo pela coisa, eliminando toda e qualquer particularidade, fazendo com que os homens estejam mais ligados pelas mercadorias que trocam do que por suas pessoas. Toda atividade produtiva é transformada em valor de troca: este é que estabelece o nexo social entre os homens, tornando-se uma relação universal e tendo como expressão geral, o dinheiro.

Karl Marx assim se expressa: “( $(.$.$) o poder que cada$ indivíduo exerce sobre a atividade dos outros ou sobre as riquezas sociais o possui enquanto é propriedade de valores de troca, de dinheiro. Seu poder social, assim como seu nexo social com a sociedade o leva consigo no bolso". (Marx, 1971)

Ao nível do indivíduo, esta subordinação em relação à coisa, transparece como indiferença, pois as relações entre os homens são marcadas e mediadas pelo valor de troca, pelo dinheiro, eliminando toda e qualquer característica pessoal dessas relações. Apesar de parecerem relação entre pessoas, são relações entre coisas.

Na aparência, esta relação é de independência pessoal ou indiferença, porém faz parte da própria essência do processo de alienação do trabalhador, que está separado dos meios de produção e de um gênero determinado de trabatho. Ele conta corpo. Trabalho e Natureza são consubstanciais ao ser genérico, é condição para se manter a espécie viva (subsistência e reprodução), é uma relação necessária e condição da história.

Na sociedade capitalista o homem trabalhador é marcado pela apropriação, do seu produto e de sua atividade, portanto de seu ser enquanto sujeito. A sua relação com a Natureza passa a ser mediada por outras dimensões (capital, mercadoria, valor de troca, dinheiro). (Marx, 1971)

Nestes termos o indivíduo tern que se pôr na sua ativi- dade principal - o trabalho - como mercadoria. É assim que se constitui como sujeito, por algo exterior a ele; não há identificação do sujeito com o objeto, portanto com a Natureza. Toda a sua sobrevivência passa pelo capital, seu corpo inorgánico é mercadoria, dinheiro. Enquanto sujeitos somos mercadoria, dimensão pertencente ao núcleo de nossas subjetividades e estruturante de nossas individualidades.

Ao internalizarmos a mercadoria, significa ter no nosso mundo interior algo que é vivenciado e subjetivizado como coisa. A alienação passa a fazer parte da estruturação de nossas subjetividades, somos atingidos ao nível do incons. ciente ${ }^{b}$.

Podemos afirmar com isto que se desenvolve um processo de naturalização da coisa, da mercadoria. Sob o ponto de vista prático, a divisão social do trabalho, a apropriação somente consigo próprio, portanto está separado da Nature. za (de seu corpo inorgânico). Há uma cisão entre o sujeito e o objeto, que é vivenciada enquanto indiferença - estranhamento - em relação aos outros, pois só temos a nós mes" mos como força de trabalho.

O indivíduo passa a precisar de alguma coisa como mediação para atingir o que era dele, algo que possa ser trocado indistintamente por tudo. O dinheiro equipara o hetereogêneo, elimina os vínculos de dependência pessoal, abstraindo as diferenças qualitativas.

Esta condição passa a ser internalizada na nossa subjetividade; o uso e o ter eliminam o ser do outro. O nexo social dos homens está na dependência material, os individuos são expressão das relações materiais que os dominam.

"Mesmo os atributos mais humanos do homem tornam-se função do dinheiro, que é o substituto geral das mercadorias (...). Suas relações mútuas são as de suas mer. cadorias" (Marcurse, 1978)

Segundo as análises de Marx, esse processo Histórico, característico da sociedade capitalista, transforma as relaçôes pessoais entre os homens em relações objetivas entre as coisas. É o que ele denomina de "o caráter de reificação das relações sociais", analisando em sua obra "O Capital" como o "Fetichismo da Mercadoria". Nesta está explícita a sua teoria do valor, base para desvendar o caráter mistificador das condições econômicas da produção capitalista ${ }^{\mathrm{C}}$.

Neste tipo histórico de produção, o trabalho, ao produzir mercadorias com um valor de troca que as iguala a qualquer outra mercadoria, adquire uma homogeneidade universal que, em sua forma histórica mais desenvolvida, tem no dinheiro a sua expressão.

Portanto, encobrem-se as relações objetivas dos indivíduos, e o que confere realidade e valor às mercadorias é aquilo que elas têm em comum: o trabalho humano abstrato, a despeito de sua aparência diversificada. Com isto, as mercadorias aparecem no mercado despojadas de toda especificidade do trabalho e se igualam pelo tempo socialmente necessário para a sua produção. Esta é a propriedade consti-

b - A questão da ideologia é discussão fundamental para aqueles que tem interesse em entender com maior profundidade esse processo de internalização.

c - Não cabe aqui desenvolver a teoria do valor mas, apenas levantar algumas questões para elucidarmos este caráter "fetichista" das relações sociais, completando as discussס̃es até aqui efetuadas e fornecer, assim, a "ponte" necessária para lançarmos algumas idéias sobre a relação da "produção artística" com este processo. 
tutiva do valor de troca e de toda mercadoria. (Marx, 1975)

O processo social de produção capitalista, ao determi. nar o valor das mercadorias, elimina a variedade do trabaIho concreto, correlativo dos valores de uso e retém, apenas, como padrão de medida, o trabalho abstrato necessário contido na mercadoria, pondo-se de lado todo o caráter qualita. tivo da produção, resultando somente a circulação.

Podemos afirmar que este processo apaga o caráter social e histórico da produção e, consequentemente, as relaç̃̃es subjetivas dos indivíduos, sob a forma de relações objetivas materiais.

Leon Rozitchener, 1982 em sua obra Freud y el problema del poder, no item "Fetichismo de la mercancía y sujeto fetichista", ao analisar esta questão, de um lado, demonstra que as relações entre as mercadorias, ao se constituírem em relações entre coisas, encobrem as relações entre os homens; por outro lado, indica o caráter metamorfosea. do do desenvolvimento da subjetividade do indivíduo, isto é, de seu aparado psíquico. A coisa é seu único prolongamen. to, desaparecendo a sua própria corporeidade e significação. As pessoas trocam o seu ser para ganharem alguns aspectos de seu ter. Desse modo, as mercadorias como fetiches supốem um modo de ser-homem fetichista, porém inconscientemente, pois esta realidade faz parte de sua corporeidade (física e psíquica), constituindo a sua identidade enquanto sujeito.

A lei do valor exerce a pressão de uma lei natural, fugindo do controle consciente dos indivíduos.

Apesar da produção capitalista ter emancipado os individuos, na medida em que entram no processo produtivo livres e iguais, enquanto uma forma histórica de produção de mercadorias estabelece uma contradição entre a existência e a essência desta realidade. Pois, o individuo só é livre para vender sua força de trabalho àquele que é livre e capaz de comprá-la. Portanto, esta "liberdade" é condição mesma da produção e perpetuação da exploração d.

Diante destas discussões, registramos uma citação de Karl Marx e uma pequena notícia de jornal que, comparadas, podem exemplificar a forma pela qual o homem, ao estar subsumido às leis da produção capitalista, perde a possibilidade de desenvolver a sua capacidade criadora, as suas potencialidade, enfim de produzir livremente e universalmente.

"O animal forma só segundo a medida e a necessidade da "species" à qual pertence, ao passo que o homem sabe produzir segundo a medida de qualquer "species" e sabe em toda a parte aplicar a medida inerente ao objeto; por is. so o homem forma segundo as leis da beleza". (Marx, 1983)

"Da crítica de arte Nery Baptista, de Curitiba, recebe o catálogo Bolsa de Arte, elaborado por ela e contendo o valor comerical aproximado de obras de artistas que vivem ou viveram no Paraná. Como qualquer outra mercadoria, ela explica que o preço final de uma obra de arte é determinado pelo mercado, que valoriza o produto de acordo com a oferta e a procura, independentemente do seu valor artístico. Os valores estão calculados em dólar, de acordo com o cambio oficial". (Folha de Londrina, 1988)

Ao utilizarmos este exemplo - da obra de arte - não temos cono objetivo desenvolver os fundamentos da análise sobre a estética em Marx, mas apenas levantar algumas questões pertinentes ao que até aqui discutimos.

Quando observamos a citação e a notícia do Jornal, percebemos uma contradição fundamental entre a natureza criadora, transformadora e ativa do homem, ressaltadas por Karl Marx, e a forma como estas dimensões se expressam na sociedade capitalista, quando a obra de arte é apenas avaliada enquanto mercadoria.

A produção material capitalista ao se opor ao homem precisamente no que ele tem de ser criador, isto é, ao ser incompativel com o trabalho livre e criador, consequente mente, o trabalho artístico, criação por excelência, perde a sua significação humana e criadora.

Na sua essência, a obra de arte, por se tratar de um trabalho peculiar, pessoal e singular, realizado pelo artista atendendo a uma necessidade essencialmente humana $e$ subjetiva de expressar, afirmar e comunicar um sentimento, uma emoção, não pode ser reduzida a uma unidade, com o fim de ser equiparada a outra, a não ser que se façam abstração de suas qualidades e propriedades sensiveis, expressadas durante o processo de criação.

Na medida em que os artistas vivem em uma sociedade historicamente determinada, a capitalista, sua liberdade de criação está marcada pelas possibilidades que ela lhe oferece. Ele é obrigado a criar e a subsistir dentro de um sistema de relações sociais dadas, determinado pelo caráter da produção material. Sendo assim, a sua criação, expressão máxima de sua subjetividade estará sujeita às leis gerais des sa produção material, submetida ao mundo das mercado rias.

A partir do momento que a obra de arte adquire de fato o estatuto de mercadoria, como bem demonstra o exemplo aqui utilizado (a notícia do jornal), desvanecemse suas qualidades concretas, seus valores de uso, sua significação humana, fundando-se em sua capacidade de produzir lucro. Isto significa que o seu valor é expresso pelo seu valor de troca, sendo ignorado e negado seu verdadeiro valor enquanto produto artístico, com qualidades estéticas.

Neste sentido surge uma contraposição de caráter histórico $e$ social entre produção artística e material, que tem a mesma origem que a oposição entre a produção capitalis ta e o trabalho livre, criadore. (Vásquez, 1978)

Sob o capitalismo, o trabalho artístico e seus produtos só interessam como objetos de troca ou produto para o mercado, e não admitem outro valor, além do que possui como mercadoria, isto é, enquanto valor de troca.

Voltando ao exemplo citado, esta situação fica clara quando a notícia do jornal estabelece que ${ }^{\prime \prime}$ o preco final de

d- Kärl Marx ao constatar este fato histórico da sociedade capitalista, indica que esta relação entre consciência e existência social, por ser falsa, deve ser superada. Por isso o caráter crítico de suas análises. 
uma obra de arte é determinado pelo mercado (...) independente de seu valor artístico".

Abstrai-se, portanto, toda a singularidade da obra de arte; o heterogêneo passa a ser equiparado pelo dinheiro, expressão universal do nexo social entre os homens; no caso em tela, os valores das obras dos artistas estão calculados em dólar, "de acordo com o câmbio oficial". O decisivo não é a atitude do artista expressa em sua obra, mas o fato de que sua criação permaneça sujeita d̀ leis gerais da produção material.

Já que o capitalismo só se interessa pela produção enquanto engendra lucro, a atividade artística e, especialmente, a obra de arte, só pode lhe in teressar enquanto produção dentro de um ponto de vista utilitário, numa relação inumana, negando o ser do homem como ser livre e criador. Desde que submetida às leis do valor, desaparecem seus nexos com o homem e sua capacidade de satisfazer uma necessidade humana especifica, não material, subjetiva, mediante suas qualidade estéticas.

A qualidade da obra de arte ou mesmo a qualidade do artista passa a repousar na sua capacidade de produzir lucro. O seu valor só é reconhecido se estiver incluído no catálogo da Boisa de Arte.
Finalizando, a afirmação de Adolfo Sanches Vásquez parece-nos apropriada para expressar esta condição do artista e de sua produção, na sociedade capitalista:

"Por ser hostil ao trabalho criador, a produção material capitalista é igualmente hostil, ainda com maior razão, ao trabalho artístico que é criação por excelência't. (Vás quez, 1978)

\section{3 - CONSIDERAÇOES FINAIS}

As questões aqui consideradas apenas lançam alguns elementos para futuros debates. Entretanto, nos pareceram importantes na medida em que permitiram um possível exercício de articulação entre a teoria marxista da alienação e uma questão prática, cotidiana e específica, vivenciada pelos artistas plásticos em geral, com relação à sua atividade e à sua produção. Portanto, revelando algumas das ambiguidades com que se reveste a relação indivíduo e sociedade.

Ao mesmo tempo, sentimo-nos instigados diante de um debate sobre os fundamentos da Estética na obra de Karl Marx, quẹ por não se tratar do objetivo central de nossas discussões, poderá se tornar objeto de futuras investigações.

\section{ABSTRACT}

Im this, alienation in the capitalist world is analysed through some texts by Karl Marx. This alienation lies beyord mere objective issues or issues related to the material production. It concerns people's 'inwardness' and is a basis for their subjectivity. The present analysis brings out important questions about the essence of the capitalist society. It also allows for the emergence of reflexions on the relation individual and society by stressing contradictions between the creative, transforming and active nature of man and the way this nature is reflected in the capitalist production. Under the laws of capitalist production, the human being is denied as a iree and creative being. Thus, one loses the possibility to develop his own potentialities and to create freely and universally.

KEY-WORDS: Alienation; Fetishism, Goods, Objectivity, Subjectivity, Individual, Society

\section{REFERẼNCIAS BIBLIOGRÁFICAS}

1 - Jornal Folha de Londrina. 5/7/88, Londrina-Pr.

2- CASTORIADIS, C. A Instituição Imaginaria da Sociedade. Rio de Janeiro: Paz e Terra, 1986. 418p.

3 - MARCUSE, Herbert. Razão e Revolução. Rio de Janeiro: Paz e Terra, 1978. 413p.

4 - MARX, Karl. Trabalho alienado e superação positiva da autoalienação humana. In: FERNANDES, Florestan (org.) Marx/ Enge/s. História. Så Paulo: Ática. 1983. p. 146-181.

5 - -_. O Capital. Crítica da Economia Política. Livro 1, Vol. I. Rio de Janeiro: Civilizaçăo Brasileira. 1975. p. 41-93.
6 - - - Elementos fundamentales para la crítica de la economia politica. In: Grundrisse - 1857-1858. Vol. I. Mexico: Siglo XXI, 1971, p. 84-94.

7. ROZITCHENER, Leon. Freud y el problema del poder. Mexico: Folios Ediciones, 1982. 93p.

8 - SILVEIRA FILHO, Paulo A. O Fetichismo da Mercadoria e Psicanálise: elementos para um debate. Revista Psicologia e Sociedade. São Paulo, 4 (2): Out. 1986. p. 8-16.

9 - VÁsQUEZ, Adolfo Sánches. As Idélas estéticas de Marx. Rio de Janeiro: Paz e Terra, 1978. 418p.

Recebido para publicação em 21/02/1991 